\title{
Some Views About Standard English
}

\author{
Jinhua Zhang ${ }^{1}$ \\ ${ }^{1}$ School of Foreign Languages, Xi' an Aeronautical University, Xi'an, China \\ Correspondence: Jinhua Zhang, School of Foreign Languages, Xi'an Aeronautical University, Xi'an, China. \\ E-mail: zjhclara@163.com
}

Received: October 30, 2019 Accepted: November 23, 2019 Online Published: November 29, 2019

doi:10.5539/ells.v9n4p94 URL: https://doi.org/10.5539/ells.v9n4p94

\begin{abstract}
English is playing an increasingly important role in the world. People can communicate through English in any place of the world, while more English varieties come into being with its spreading. Therefore, many people are confused about whether there is Standard English and what it is. Meanwhile, many people discuss that whether it is good to insist Standard English. Many arguments about these issues are continuing. This paper will review the previous studies about Standard English and present different views about it from different aspects. It is raised that although there are many arguments about Standard English, it is necessary to insist a norm for English.
\end{abstract}

Keywords: English varieties, Standard English, views

\section{Introduction}

English is increasingly important in the world, which has become the world language. It is necessary to learn English for everyone because it is a tool to communicate with people from other countries. Therefore, an increasing number of people began to learn English. However, with more people learning English, more kinds of English varieties emerge. As we all know, there are many kinds of English, such as American English, British English, Singapore English, Indian English, and Philippine English. In China, everyone is required to learn English when they are very young, but few people care which variety of English they intend to learn. Some teachers may prefer British English so they teach British English while some teachers may prefer American English so they teach American English. Each student may have received many kinds of English instruction, so the language they have learned is the mixed English. However, when a person's English competence is judged, the word "standard" is always regarded as a kind of comment while few people can tell us what the exact "standard" is.

This paper reviews the previous studies about English use in the world and presents different views about Standard English from different scholars. This paper will give us an overview of Standard English, trying to clarify the argument about Standard English. And it will try to arouse people's attention about Standard English.

\section{The Brief Introduction of English}

English originates in England during the Anglo-Saxon period, and is now spoken as the first or second language in many countries all over the world, many of which have developed one or more "national standards". English is the first language for the majority of the population in a number of countries, including the United Kingdom, the United States, Canada, Ireland, Australia, and New Zealand and it is an official language in many other countries, including India, Pakistan, the Philippines, South Africa and Nigeria. As the result of historical migrations of English-speaking populations and colonization, and the predominant use of English as the international language of trade and commerce, English has also become the most widely used second language (Oxford, 2013). No doubt English is truly the world's leading language today. It is used on all continents. In surprisingly many countries (more than 100, according to recent estimates) it has important internal functions as a "Second Language" (Schneider, 2013).

In the end of the 20th century, some scholars divided the world into three parts according to the extension of English. The first part is ENL region where English is their native language. The Great Britain, America, Canada, Australia are included in this part. The second part is ESL region where English is their second language. India, Philippine and Singapore are included. And the third part is EFL region, including China, Japan and Sweden. In this region, English is a foreign language (Wang, 2003). 


\section{The Current Situation of English Use}

Wherever you go on this globe, you can go along with English. Either most people speak it anyhow, or there is at least somebody around who can communicate in this language. And then, you may realize that mostly there's something you may find odd about the way English is used there. If you are abroad, English is likely to be somewhat different from the way you speak it (Schneider, 2013). Some people use strange words which are pronounced differently. Sometimes people build their sentences in ways that will seem odd to you in the beginning. We can see that English is not just "one language" and it is quite different in many countries and localities.

From our school days, most speakers of English retain a rather monolithic concept of what English is. We are taught that there is a "Standard English" which is correct, "good" and fixed (Schneider, 2013). We are taught how to construct a sentence, how to write a passage and how to pronounce. We are informed what is right in language and what we should do in writing and pronouncing. However, according to our observation, people just talk differently, depending on whom they are, where they live, whom they are with. Actually, there are many ways of saying the same thing and we cannot say which one is superior to or worse than any other.

When we write "I seed it" or "I seen it", others will definitely say you are wrong and it should be "I saw it". Actually, the former two sentences exist. "I seed it" is the dialect in Virgina and "I seen it" is the dialect in Pennsylvania. And also, no one will think we can say "I is seen him". Teacher must correct you that it should be "I did see him". However, it is used universally among African Americans (Schneider, 2013).

Holliday (1994) raised that the use of English can be divided into two categories: native speakers and non-native speakers. The countries of native-speakers can be called inner circle including Britain, Australia, and North America. Quirk (1990) said the countries of non-native speakers can be divided into two parts: outer circle and expanding circle. Outer circle refers to countries like Singapore and India in which English is a second language. Expanding circle refers to countries like China and Japan in which English is a foreign language.

In countries where English is not either a native language or is not widely spoken, a non-native variant (typically English English or North American English) might be considered "standard" for teaching purposes (Trudgill \& Hannah, 1982).

\section{The Different Views to Standard English}

The standard is from industry. It is used to assess product quality; precision may be established on features of measurement and accuracy. The assessment of conformity to the standard rests on criteria upon which independent judges will universally agree (Phillips, 1999). For English, there are many arguments about whether there is a standard in English and how to define it.

Many scholars have talked about Standard English from both positive and negative aspects. McArthur (1992) said Standard English belongs to a small number of people who are in the dominant status in Britain. It has been received in the whole country without the regional features and class features. It is easy to see the features of Standard English in print. And most radio, TV station and Internet use Standard English. He also raised that the Standard English relates to the education level and what a middle school student says can be regarded as the Standard English. While Peter Strevens gives the definition from the negative aspect. Strevens (1981) raisedsome assumptions. He said "Standard English" cannot be defined or described in terms such as "the best English", or "literary English", or "Oxford English", or "BBC English". And it is not defined by reference to the usage of any particular group of English-users, and especially not by reference to a social class- "Standard English" is not "upper-class English" and it is encountered across the whole social spectrum, though not necessarily in equivalent use by all members of all classes. He also thought it is not statistically the most frequently occurring form of English, so that "standard" here does not mean "most often heard". And it is not imposed upon those who use it. He agreed that the use of Standard English by an individual may be largely the result of a long process of education but Standard English is neither the product of linguistic planning or philosophy nor is it a closely-defined norm whose use and maintenance is monitored by some quasi-official body, with penalties imposed for non-use or mis-use. Standard English evolved: it was not produced by conscious design. We can see some of their views are opposite. McArthur holds that Standard English belongs to people in the dominant class while Strevens do not think that Standard English is upper-class English.

Many scholars defined Standard English from different aspects such as geographical distribution, function, and form. Strevens (1981) defined Standard English as "a particular dialect of English, being the only non-localized dialect, of global currency without significant variation, universally accepted as the appropriate educational target in teaching English: which may be spoken with an unrestricted choice of accent." The kingman Report 
(1988) held that Standard English is the written forms used by every English writer no matter which dialect region the writer is from. Because it is the unified written form, it has the standard. This written form can be used in Britain and the world. David Crystal (1997) said that Standard English is not restricted in a certain region. Standard English is mainly about the grammar, vocabulary and orthography but is irrelevant to pronunciation. He thought that it is okay for people to use different accents. Standard English is the most prestigious language form in Britain so some people advocate to teach it in school and to use it in administrative department, judicial office and all kinds of media. He said that Standard English is known universally but not everyone speaks Standard English and writes Standard English. Most people use regional dialect but a small number of people speak Standard English. And also, American Standard English is different from British Standard English.

Standard English has attracted so many attentions from scholars but why it is so hot to be discussed. Strevens (1981) raised that "the term 'Standard English' is valuable for three reasons: (1) it provides a way of accounting for a range of observable distinctions and attitudes; (2) it offers a label for the grammatical and lexical components, at least, of the teaching core undertaken by the profession of teaching English, whether as the mother tongue or as a foreign or second language; (3) it constitutes the unifying element within the enormous diversity of the English language".

Actually, many people doubt that whether it is good to set a certain English variety as the Standard English. Because of different culture and environment we live in, our language must be influenced. Rowley (1978) thought that it is not strange to hear and see new English forms in other countries because the English form used follows their environment and meets the cultural demand of a certain country. But many people may be afraid that they will be laughed at because their English is not like what people in some certain areas speak, so they always pursue the "Standard English".

There are two opposite views about the appearance of different dialects. Jiang (1995) proposed that this "English crisis" has existed for a long time. He said Quirk worries about the deterioration of the English standard while many other people insist the independence of their English. Quirk advocated the only standard for English use but Kachru advocated receiving different standards of English in different countries and regions in the world.

Some people think the British government has the obligation to maintain the authority and unification of English, because the English instruction is not only an academic industry but also an important source of foreign exchange for the tertiary industry. The representative figure of this view is Quirk. He thought that "standard" can only be used in Standard British English and Standard American English, so he held that only these two kinds of English can be learned as the international language. English teacher in other countries should teach strictly according to these two kinds of English.

However, Kachru disagreed with this view. He thought English is developing all around the world. The most important function of English is communication in society. And all the languages have their own standard which may be different from the Standard British English and Standard American English. This new standard must be easier for people in other countries. Therefore, it is easier and more convenient to learn. It must be a release for people in other countries and in his view, these new standards should be regarded as the same status with Standard British English and Standard American English.

However, another reason for disagreeing these new standards is that English may face a big challenge. We know that Latin has disappeared and many other languages such as French, Italian and Spanish have replaced it. Many scholars worry that English is facing the same situation at present and we cannot guarantee English will not be replaced by many other English varieties with new standard.

In the second half of 20th century, the concept of international English comes into being. It refers to the standard form of English and can be used as the unified language which is used in teaching and learning in the world (McArthur, 1998). It means that international Standard language is a unified language in the world and Standard English is not a certain variety in some countries. At the same time, the base of international English standard is argued. People try to search the standard of the international Standard English. Some people think it should set the vernacular in Britain and America as examples. But even in Britain and America, there are so many varieties and the standard of their language is not very clear.

\section{The Future of English}

Under the demand of the international communication, the internationalization of English is determined by more and more international communication. Therefore, English spreads all over the world. Meanwhile, English is used by different people from different countries, so English is influenced by their culture. More varieties will emerge in the world. Although we cannot control the emergence of the varieties, we still can regulate the norms 
for them. Yang (2003) raised that although we cannot limit the emergence of English variety, it must have a basic restriction which can be called the norm. It is necessary to follow the norm for every English variety. Norm does not need a serious and concrete boundary because it includes every English variety which can be understood and used to communicate by others (Madsen, Harold, \& Donald Bowen, 1982).

Strevens (1981) raised that "the assertion that Standard English dialect is universally accepted as the appropriate model for educational use is a verifiable fact". However, he also reminded that "although Standard English dialect is universally accepted as the educational target, no single accent fills an equivalent position" and "the tacit acceptance of Standard English dialect for educational purposes does not mean that it is 'best' in some universal sense".

A recent estimate puts speaker numbers close to two billion. One of the main reasons for all of this is that in many developing countries people from all walks of life perceive English as the primary gateway to better jobs and incomes, thus a better life. In the future, this number will be increasingly large and the varieties of English will also be more and more.

\section{Conclusion}

In China, a kind of new English variety emerges gradually. Some words and sentences called Chinglish in the past have got their status nowadays. Many foreigners have received some of our English and many people call it as China English. Although English has been influenced by our language and culture, we still need to learn the "Standard English". We still advocate standard British English and standard American English . Based on this, many students may set their own standard according to their preference and their personal development. We cannot say which kind of English is standard or which kind of English is superior but it is a fact that BBC English and VOA English have higher prestige in the world.

As the world lingua franca, English has played an important role in international communication. According to Crystal (2001), two thirds of prints are published in English, 90\% scientific papers are written and read in English and it is the first choice for international agreement and contracts.

With the spreading of English, many varieties will emerge in many other countries. Although people still can understand their 'English' and the basic communication is not influenced, the changes happened to English will still exist. We cannot know what will happen to English in the future, but it is certainly changing all the time. The arguments about "Standard English" will continue. And it is necessary to insist some norms about using English

\section{References}

Crystal, D. (1997). The Cambridge Encyclopedia of the English Language. Cambridge University Press.

Crystal, D. (2001). English as a Global Language (vol. 2, pp. 60-61). Beijing: Foreign Language Teaching and Research Press.

Holliday, A. (1994). Student culture and English language education: An international perspective. Language, Culture and Curriculum, 7(2), 125-143. https://doi.org/10.1080/07908319409525172

Huang, Y, L. (2008). The study about changes of Standard English. Heilongjiang Science and Technology Information, 25, 163-164.

Jiang, Y, J. (1995). Reviews about the study of World Englishes in recent twenty years. Foreign Language Teaching and Research, 3, 13-19, 80.

Kachru, B. (1991). Liberation linguistics and the Quirk concern: a reply to language varieties and the standard language. English Today, 7(1), 3-13. https://doi.org/10.1017/S026607840000523X

McArthur, T. (1992). The Oxford Companion to the English Language. Oxford University Press.

McArthur, T. (1998). The English Language. Cambridge University Press. https://doi.org/10.1017/9780511621048

Oxford. (2013). Oxford Dictionaries Online. Retrieved from http://www.Askoxford.com

Phillips, J. K. (ed.) (1999). Foreign Language Standard: Linking Research, Theories, and Practices. National Textbook Company.

Quirk, R. (1990). Language Varieties and the Standard Language. English Today, 6(1), 3-10. https://doi.org/10.1017/S0266078400004454

Schneider, E. W. (2013). English Around the World. Cambridge University Press. 
Strevens, P. (1981). What is 'Standard English'? RELC Journal, 12(2), 1-9. https://doi.org/10.1177/003368828101200201

Tian, Z, J. (2007). Norms of Standard English to World English. Journal of Hebei Normal University $\begin{array}{lllll}\text { (Philosophy and Social } & \text { Sciences }\end{array}$ https://doi.org/10.3969/j.issn.1000-5587.2007.06.018

Trudgill, P., \& Hannah, J. (1998). International English: A guide to varieties of English (pp. 1-2). London: Edward Arnold.

Wang, Z, Y. (2003). A collection of language problems. Foreign Language Teaching and Research Press.

Yang, G, J. (2003). Arguments about Standard English. Foreign Language Education, 24(1), 36-38.

Zhang, Y. (2004). The study of Standard English: China English and Chinglish. Journal of Jimei University, 5(1), $72-77$.

\section{Copyrights}

Copyright for this article is retained by the author, with first publication rights granted to the journal.

This is an open-access article distributed under the terms and conditions of the Creative Commons Attribution license (http://creativecommons.org/licenses/by/4.0/). 